\title{
Regional Agricultural Underdevelopment in Pakistan
}

\author{
MOHAMMAD ASLAM ChaUdHARY
}

\section{INTRODUCTION}

In this study an attempt has been made to analyse regional agricultural growth in Pakistan in the light of the regional spread of the Green Revolution and its impact on productivity and output growth of this sector. The regional inequality in the spread of the Green Revolution can lead to several other inequalities and it may cause social and economic problems, for example, inequality in income, social tension and political unrest. Therefore, its study is important. Our main focus of the study is to identify linkages between the regional spread of the Green Revolution and increase in productivity in the agriculture sector. Such an inequality in the growth of agriculture could also be a source of relative under development of a certain region. To study such events and for comparison, an analysis of all the regions of Pakistan has been carried out.

Table 1, shows inequality in the growth of agriculture in Pakistan and in its regions since $1960-61$ to $1990-91$.

There was rapid growth in agricultural output during the 1960s. However, it slowed down thereafter. A noticeable change is that this growth is marginal during the 1980s. It is important to investigate the sources of regional differences in this growth and changes over time. Regional differences in the growth of agricultural productivity may be seen from Table 1 . What could be the source of this inequality in Agriculture is very important for agricultural expansion and policy formulation. To investigate this problem Part II of this study provides a brief theoretical rationale. Part III, offers the source of agricultural growth as well as the speed and the spread of the Green Revolution. Part IV, consists of the conclusion and possible policy implications.

Mohammad Aslam Chaudhary is Associate Professor at Quaid-i-Azam University, Islamabad. Author's Note: I am thankful to the university authorities for providing partial funding for this study. The views expressed entirely belong to me. Due to space limitation, only a summary and major findings of the study are presented here. I am thankful to Dr M. Ghaffar Chaudhry for his valuable comments on the study. 
Table 1

Regional Growth of Agricultural Productivity

(Weighted Average per Hectare)

(Percent)

\begin{tabular}{lrcc}
\hline & $1960-61 /$ & $1971-72 /$ & $1980-81 /$ \\
Region/Year & $1971-72$ & $1979-80$ & $1990-91$ \\
\hline Pakistan & 52.94 & 24.27 & 09.00 \\
Punjab & 35.90 & 20.30 & 09.90 \\
Sindh & 118.40 & 27.30 & 02.00 \\
NWFP & 37.60 & -2.00 & 09.89 \\
Balochistan & 137.50 & 80.70 & 08.50 \\
\hline
\end{tabular}

Source: Government of Pakistan (Various Issues).

\section{THEORETICAL BACKGROUND}

During the last three decades (1960s, 1970s and 1980s) major changes have taken place in world agriculture. In less developed countries, the so-called Green Revolution, the development and diffusion of modern varieties of rice, wheat and other crops with higher use of fertiliser combined with optimal water application, generated high yielding capacity and resulted in an appreciable impact on aggregate output. Ruttan and Hayami (1985) identified these elements.

A study of Indian agriculture by Sen (1974) stated that the technical characteristics of modern varieties of seeds appeared to hold out a substantial increase in the rate of growth of foodgrains in the underdeveloped countries. It seems to indicate that the use of modern inputs was a major source of rapid increase in agricultural productivity. Reitsma and Kleinpenning (1985) defined the Green Revolution as follows:

\footnotetext{
"By Green Revolution we mean ... the use of new genetically improved varieties of food crops which are capable of producing much greater yields than traditional varieties. .. In order to obtain the high yields, ample use must be made of other inputs, including artificial fertiliser, pesticides and insecticides. Another prerequisite is the availability of adequate amounts of irrigation system".
}

The above passage indicates three important points (i) the main ingredients (inputs) of the Green Revolution are HYVs, fertiliser, pesticides and irrigation; (ii) simultaneous and optimal use of these inputs is necessary to buying about significant increases in agricultural production. 
The Green Revolution in Pakistan started in the early 1960s. Some of the modern inputs were introduced in the late 1960 s. It was mainly introduced by the public sector. In Pakistan, distribution of HYVs, fertiliser, pesticides and irrigation were controlled by the public sector. PASSCO was responsible for the distribution of HYVs and pesticides. Expansion of the irrigation network was done by WAPDA and Canal Department. Ahmed and Amjad (1985), regarding the spread of Green Revolution in Pakistan, stated as follows:

"The change in emphases in government policy, which was initiated in the early sixties, coincided with the advent of the so-called 'Green Revolution'. This revolution started with a scientific and technological breakthrough in the form of inputs, like high-yield varieties of seeds (HYV), fertiliser, greater spread of agricultural mechanisation, mainly in terms of tubewells and tractors." All the above indicated variables will be analysed to see their speed and spread over time.

\section{THE SPREAD OF THE GREEN REVOLUTION}

\section{(i) HYV Seeds}

In Pakistan, the Green Revolution was initiated in the late 1960s and widely spread during the late 1970s and early 1980s. However, the momentum of the Green Revolution slowed down during the 1980s. As indicated in Table 2, other distribution of HYV seeds in Pakistan during the 1980s was not satisfactory. Its growth was only 17.4 percent during this period. In other words, during the 1980s the distribution of HYV seeds grew by only 1.74 percent per annum, which is not a satisfactory performance. The growth of the same was -11.7 percent in Punjab and $\mathbf{- 3 5 . 3}$ percent in Balochistan which, means that rather than ancrease it actually decreased. The same increased by 75 percent in Sindh and 29 percent in NWFP. To reach a clear outcome it is necessary to analyse the same in depth. For this purpose, the spread of HYVs is analysed for major crops i.e. wheat and rice.

\section{Wheat}

Overall in Pakistan, by 1970-71, about 57 percent of the total area of wheat was sown with HYVs (of wheat). It reached 90 percent by 1984-85 and 92 percent by 1989-90. Thus, during the late 1980s only 2 percent additional area was brought under HYVs cultivation. At the regional level, by 1989-90, Punjab and Sindh had 96 percent of their wheat area cultivated with HYVs. It may be noted that only three percent in Punjab and no additional area in Sindh was brought under HYV cultivation, in the late 1980 s. On the other hand, during this period, there was a 
decrease of 5 percent and 15 percent in the same in NWFP and Balochistan, respectively. Thus, at the regional level, NWFP and Balochistan failed to reap the additional benefits of these HYVs. The yield did not increase much during 1980s as compared to the previous decades. Regional details of the growth of yields may be seen in Table 2 .

Table 2

Spread of HYVs and Changes in Yield

(Percent)

Growth of all HYVs

Distribution (1980-81/

1989-90)

$-11.70$

75.10

$29.20 \quad-35.30$

17.40

\section{Wheat}

Pencentage of Cropped

Area Sown with HYVs

$\begin{array}{llllll}1970-71 & 58.00 & 68.00 & 45.00 & 10.00 & 57.00 \\ 1981-82 & 88.00 & 96.00 & 65.00 & 62.00 & 85.00 \\ 1984-85 & 93.00 & 96.00 & 71.00 & 64.00 & 90.00 \\ 1989-90 & 96.00 & 96.00 & 66.00 & 49.00 & 92.00\end{array}$

Growth Of per Hectare

Yield

$\begin{array}{rrrrrr}1971-72-1984-85 & 2.30 & 21.30 & 18.70 & 28.50 & 02.70 \\ 1984-85-1989-90 & 13.40 & 01.60 & 13.60 & 19.70 & 03.20\end{array}$

Rice

Percentage of Cropped

Area Sown

$\begin{array}{rcrrrr}1972-73 & 18.00 & 70.00 & 6.00 & 60.00 & 41.00 \\ 1980-81 & 95.30 & 79.00 & 33.40 & 73.20 & 86.20 \\ 1984-85 & - & 83.50 & 40.00 & 95.60 & 87.70 \\ 1989-90 & 99.00 & 83.50 & 47.40 & 93.20 & 52.50\end{array}$

Percentage Change of

Yields of HYVs

$\begin{array}{rrrrrr}1972-73-1984-85 & -8.90 & 8.20 & -6.40 & 87.10 & 80.50 \\ 1984-85-1989-90 & -14.60 & 6.50 & 2.40 & -14.50 & 01.90\end{array}$


Rice

Table 2 also provides the spread of HYVs of rice and its performance during the 1970s and the 1980s. Overall in Pakistan, the area sown with HYVs of rice was 41 percent in 1972-73, which increased to 86 percent in 1980-81. The same increased to 81 percent in $1984-85$ and decreased to 52.5 percent during the late 1980s. It appears that the spread of HYVs of rice deteriorated during the late 1980s. A similar trend was also apparent for wheat. The regional pattern of HYVs coverage of rice was also not very satisfactory during the 1980 s but followed almost the same pattern similar to that of wheat. The growth of yields was zero percent in Sindh and -2.4 percent in Balochistan. The productivity growth of HYVs was also not very encouraging during the late 1980s. The per hectare production of HYVs rice increased by only 1.9 percent in the late $1980 \mathrm{~s}$. It was negative $(-14.6$ percent) in the province of Balochistan. It is important to note again that neither the yield nor the spread of HYVs of rice were satisfactory during the late 1980s which lead us to conclude that the momentum of the Green Revolution slowed down during the 1980 s and the desired benefits could not be reaped. It may also be noted that the findings of analysis above coincided with the slow down of aggregate productivity growth during the 1980s (Table 1).

\section{(ii) Consumption of Fertiliser}

The second most important variable of the Green Revolution is consumption of fertiliser, It may be noted that fertiliser consumption significantly increased in all the provinces during the $1970 \mathrm{~s}$. However, this process of accelerated use of fertiliser did not continue during the 1980s. The per hectare use of fertiliser in Pakistan was only 54 Lbs., in 1972-73 which increased to 128.5 Lbs., by 1981-82. It constituted 134 percent growth in its consumption. The same trend continued during the 1980s and its use reached 193.4 Lbs. Thus, during the 1980s the percentage change in its consumption was only 59 percent which is almost 2.3 times less than that of the same growth during 1970s. It indicated that the growth of consumption of fertiliser slowed down during the 1980s as compared to the 1970s. It may also be noted that this slow down in its growth is not due to the reason that its use in Pakistan reached its peak and it was not beneficial to use it further. The use of fertiliser is three times more in DCs, as compared to Pakistan. Thus, there is still a need to increase its application. Although the consumption of fertiliser at the regional level increased significantly but its growth slowed down during the 1980s, as compared to the 1970s. Again a deteriorating trend in the spread of this variable was observed, over time. 
(iii) Use of Pesticides and Area Sprayed

The spread of pesticides and protection against crop disease is a reflection of the contribution of the Green Revolution. The spread of these chemicals was not encouraging till 1970s. The use of pesticides was not common in the early 1980s too. In 1982, only 2.7 percent, 12 percent, 11 percent and 5 percent of the total cropped area was sprayed in Punjab, Sindh, NWFP and Balochistan, respectively. Overall in Pakistan the figures for the same were only 5.4 percent which is not satisfactory by any standard. However, it is important to note that a relatively greater percentage of the cropped area was sprayed in NWFP and Balochistan, as compared to Punjab and Sindh. However importance should not be placed on the figures for NWFP and Balochistan as there is a very small cropped area in these provinces, as compared to Punjab and Sindh.

Overall the use of pesticides increased during the 1980s. By 1989-90, about 12 percent, 13 percent, 3 percent and 5.3 percent of the cropped area was sprayed to protect from disease in Punjab, Sindh, NWFP and Balochistan, respectively. The figures for the same for Pakistan overall were 11.3 percent which were almost double than that of the 1980s. It is important to note that again during the 1980s the use of pesticides either slowed down or its growth remained constant as compared to 1982 (except for Punjab).

Overall in Pakistan, the distribution of pesticides increased during the 1980s. In 1979, about 883.3 tons of pesticides were distributed. It increased to 12737 tonnes by the end of 1988 . Thus, during this period, it increased by more than fourteen folds. However, the per hectare use of pesticides was about one kilogram which is still very low.

\section{(iv) Irrigation and Water Supply}

Irrigation and water supply at the farm gate is one of the most important variables for reaping the benefits of the Green Revolution. Neither the seeds nor the fertilisers can function efficiently without the optimal use of water. HYV seeds are very sensitive to water supply. The failure to use the required water application may result in the reduction of productivity or even it could be lower than the traditional yield. However, ample supply of water may also raise the productivity of traditional seeds upto a certain extent. Therefore, the impact of the Green Revolution can only be seen by the simultaneous use of all the variables. Irrigation facilities, except private tubewells, were mainly controlled by the public sector. Its performance is directly affected by the public sector. 
The irrigated area in Pakistan during the 1970s increased slightly. The same area increased by 1.6 percent in Punjab and 40 percent in NWFP. There was a marginal change in Sindh. There was still about 20 percent of the cropped area which did not have irrigation facilities. It indicated that irrigation, being one of the important inputs, did not increase much during the 1980s.

\section{(v) Agricultural Credit}

In 1972-73, the per hectare disbursement of agricultural credit was Rs. 19 in Punjab, Rs 42 in Sindh, Rs 8 in NWFP and Rs 28 in Balochistan. During 1982-83 the same increase to Rs 106, Rs 159, Rs 53 in Punjab, Sindh and Balochistan, respectively. However it did not increase much in NWFP. The increase in the same during 1980s constituted to 82 percent for Punjab, 80 percent of Sindh, -3 percent for NWFP and 185 percent for Balochistan. It indicated that although the growth of credit seems encouraging, but, its concentration in a few hands and misuse hardly leads to the overall improvement of agriculture. However, its role in development could not be denied.

\section{CONCLUSION}

Our analysis of regional agricultural growth and underdevelopment offers several insights. The provinces differ in the spread of the Green Revolution and as a result differ in productivity levels. Higher increase in productivity is supported by widespread Green Revolution. The spread of modern inputs slowed down during the 1980s and as a result, the growth of output also slowed down. The absolute level of modern inputs is very low in Balochistan and NWFP, despite fast growing productivity.

Thus, as a policy implication, it is important that modern inputs need to be widely introduced in these provinces. It may be inferred that the difference in productivity could generate regional income inequalities in Pakistan. Thus, optional functioning of the economy and equity demands that neglected areas, need to be brought into the mainstream. It may also be noted that the overall speed of the Green Revolution has slowed down. It is important that its momentum must be maintained so that desired results could be achieved.

\section{REFERENCES}

Ahmed, V., and R. Amjad (1985) The Management of Pakistan Economy, 1947-82. Oxford University Press. 
Pakistan, Government of (Various Issues) Agricultural Statistics of Pakistan 197985, 1990-92. Islamabad: Agriculture and Cooperatives, Food and Agriculture Division.

Pakistan, Government of (Various Issues) Pakistan Economic Survey. Islamabad: Pakistan, Ministry of Finance, Economic Advisers Wing.

Reitsma, H. A., and J. M. G. Kleinpenning (1985) The Third World in Perspective. Rowmon D. Allanheld.

Ruttan, W. Vernon, and Y. Hayami (1985) Agricultural Development. Baltimore: the John Hopkins University Press.

Sen, B. (1974) The Green Revolution in India. New York: Wiley Eastern Prt., Ltd. 


\section{Comments on}

\section{"Regional Agricultural Underdevelopment in Pakistan"}

The paper, deals with an important theme and may have made a contribution to the existing body of knowledge on the subject. The main objectives of the paper were to explore the impact of the Green Revolution on agricultural productivity in the various provinces and consequently derive implications for income distribution. A, more or less, decade by decade analysis of agricultural output and inputs was undertaken to study the discontinuity of the Green Revolution as an engine of growth in Pakistan's agriculture.

Although the objectives are quite noble, the paper is highly incapacitated to explore them appropriately. Apart from the faulty manipulations of the available data, many of the conclusions of the paper seem to be unwarranted, mere assertions and unsubstantiated claims. The paper is badly written and needs serious editing. My detailed comments and/or suggestions on the paper are as follows:

First, the paper holds that, although agriculture flourished very rapidly during the 1970s, the trend has receded in the 1980s. On the basis of this hypothesised trend in production, the paper also concluded that the Green Revolution as an engine of growth is running out of steam. While provincial value-added data are not available, Pakistan-wide evidence totally belies these conclusions as growth rates of agricultural output between 1980-81 and 1990-91 exceeded 4.04 percent per annum against the corresponding rate of 2.89 percent for the $1970 \mathrm{~s}$. Perhaps the conclusion follows from Table 1 given by the author. The table reports the aggregate growth of agricultural productivity separately for 1960-61 to 1971-72, 1971-72 to $1980-81$ and $1980-81$ to $1990-91$. It is not clear how this table was calculated and what weights were used? Obviously the table (if not also the paper) is an updated version reported in a specific part of the author's book cited in the paper. According to this book, the table was calculated by weighting the production of individual crops by their respective percentage area in each of the regions. The weighting scheme being faulty is likely to yield spurious and inconsistent results. An appropriate way of generating consistent time-series data on agricultural productivity is to multiply the production of individual crops by their respective prices, calculate total gross value of all crops and divide it by the total area of crops 
for each year under consideration. Without following the appropriate calculation procedures, it seems vague to explore any trend in agricultural productivity.

Second, the paper makes interperiod comparisons of growth performance of output and consumption of particular inputs. Unless the timespan of each period is kept uniform, the validity of such comparisons is questionable. It is sad that the author fails to recognise the significance of this point as timespans vary considerably between various periods. For example, in Table 2, total growth of yields of wheat and rice over a twelve-year period between 1972-73 and 1984-85 is compared with that of a five-year period 1984-85 to 1989-90. While paucity of data for a certain year may be the most proximate cause for varying the timespan, the paper would have made more sense, had such comparisons been based on annual growth rates for each of the periods under consideration.

Finally, the paper's conclusion that the inequality in the spread of the Green Revolution may a source of regional inequality seems to be equally untenable. I do not think that the paper contains enough appropriate evidence to reach that conclusion. This follows partly from the points discussed above and partly from lack of any direct evidence on income distribution in the paper. In fact, whatever incomplete information is included in the paper points to the contrary. For example, although Balochistan is the poorest province of Pakistan, it reaps the highest wheat and rice yields (Table 2) and has the highest growth rates of agricultural productivity since 1960-61 (Table 1). The rapid growth of agricultural productivity in Balochistan was also backed by the high growth rates of irrigation water usage and fertiliser unknown elsewhere in Pakistan since 1972-73. In the light of such clear evidence, it is naive to argue that the productivity level is low in Balochistan or that the poor spread of the Green Revolution in Balochistan was responsible for the accentuation of regional income inequalities.

Pakistan Institute of

M. Ghaffar Chaudhry

Development Economics, Islamabad. 